\title{
Ulcerative colitis in a neovagina
}

\author{
Anas Alsaleh ${ }^{1}$, Ramy Eid ${ }^{2}$, Michael I dowu ${ }^{3}$, J ohn F. Kuemmerle ${ }^{1}$ \\ 1. Division of Gastroenterology, Hepatology and Nutrition, Department of Medicine, Virginia Commonwealth University, \\ Richmond, United States. 2. Gastrointestinal Specialists, Inc. Richmond, United States. 3. Division of Anatomic Pathology, \\ Virginia Commonwealth University, Richmond, United States
}

Correspondence: John F. Kuemmerle. Address: Division of Gastroenterology, Hepatology and Nutrition, Virginia Commonwealth University, P.O. Box 980341, VA 24298, Richmond, United States. Email: john.kuemmerle@vcu.edu

Received: March 10, 2014

DOI : $10.5430 /$ crim.v1n2p89
Online Published: April 10, 2014

URL: http://dx.doi.org/10.5430/crim.v1n2p89

\section{Abstract}

We report a case of ulcerative colitis developing in a colonic transposition used for creation of a neovagina in a patient with congenital Muellerian agenesis. The onset of vaginal disease preceded the development of colonic disease and was more resistant to treatment compared to the colon disease failing multiple escalating therapies. Patient is currently in remission on biologic therapy.

\section{Keywords}

Ulcerative colitis, Neovagina, Vaginoplasty

\section{I ntroduction}

Vaginal agenesis occurs about 1: 4000 to 1:10000 females, the most common cause is congenital absence of the uterus and vagina which is also referred to as Muellerian agenesis ${ }^{[1]}$. The first line approach to treatment is usually non-surgical using successive dilation, with surgery reserved for patients failing or refusing dilation ${ }^{[2]}$, available surgical options include creation of neovagina using skin graft or utilizing bowel segments for creation of a neovagina, the most commonly utilized bowel segment is the sigmoid colon ${ }^{[1,3]}$, peritoneum, bladder mucosa, amnios grafts have also been used for creation of a neovagina in pediatric patients ${ }^{[4]}$. Bowel segments used to construct neovagina provide the advantage of a cosmetic, self-lubricating vagina without the need for prolonged vaginal dilation, long term functional results are usually favorable ${ }^{[5,6]}$.

\section{Case report}

We report a case of 29 year old female with history of congenital Muellerian agenesis with agenesis vagina and lower uterine segments. At age 16 the patient underwent construction of neovagina using colonic transposition. Transverse colon was used because of technical reasons intra-operatively. Following surgery patient did well with good functional outcome, however, at age of 25 she started having vaginal bleeding. She was evaluated by her gynecologist and found to have inflammation in the neovagina. No specific diagnosis was given the patient but she was treated with antibiotics without improvement in the symptoms. Three years later patient started noticing rectal bleeding, at that time she was evaluated by a gastroenterologist who performed colonoscopy and endoscopy of the neovagina (see Figure 1). Severe colitis was 
present in the neo-vagina and moderate colitis in the left colon on histopathology (see Figure 2). The right colon was normal.

Her colonic disease was easily controlled with mesalamine enemas, however, her vaginal disease didn’t respond to mesalamine enemas or suppositories, hydrocortisone enemas, oral corticosteroids or 6-mercaptopurine. Following that infliximab infusions were initiated and since then the patient's colitis and neovaginal inflammation is in remission and the patient is asymptomatic.

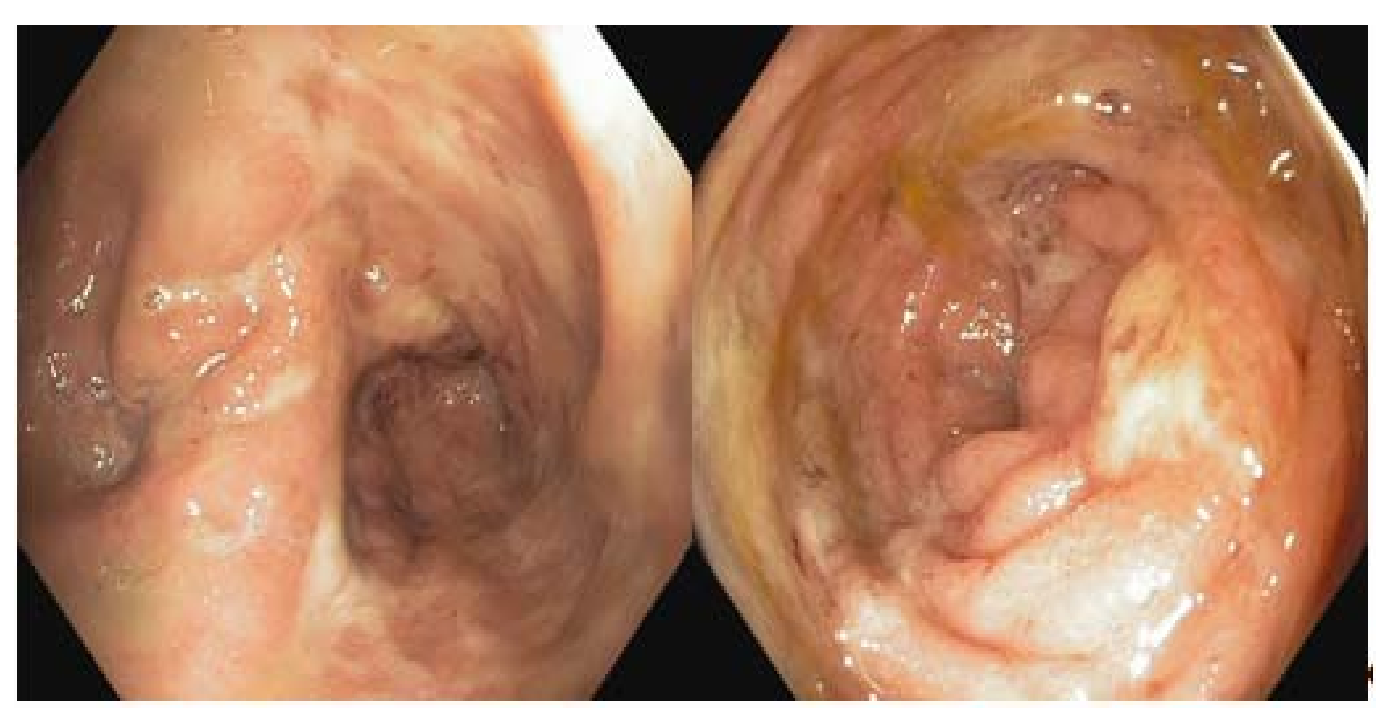

Figure 1. UC in the neovagina (left) and in the colon (right).
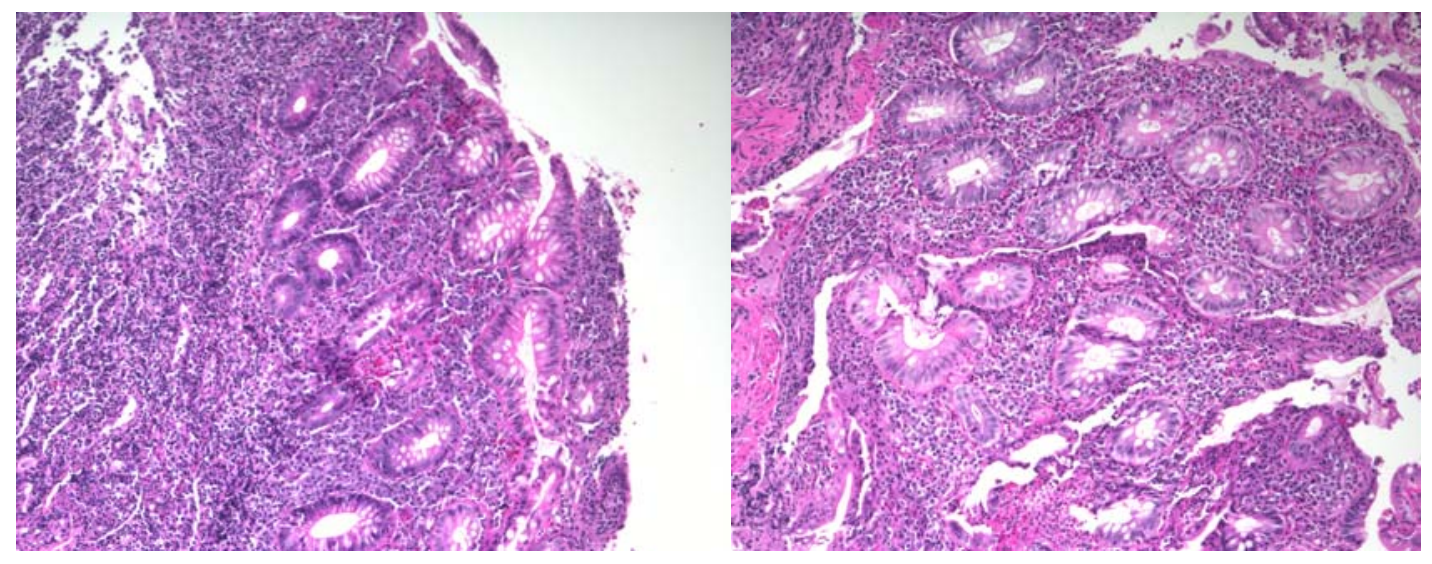

Figure 2. Histopathology demonstrating active colitis in the neovagina (left) and distal colon (right).

\section{Discussion}

Diseases of the colonic mucosa continue to happen in the neovagina following reconstruction, adenocarcinoma of the colonic mucosa has been reported in the neovagina ${ }^{[7,8]}$, several case reports have reported ulcerative colitis in both the colon and the neovagina after neovagina creation for persistent cloaca, gender reassignment, reconstruction following surgical excision of vagina and androgen insensitivity syndrome ${ }^{[9-12]}$.

Management of ulcerative colitis in the neovagina is challenging since oral 5-Aminosalicylates exert their effect locally rather systemically and thus won't be effective for vaginal disease, topical 5-Aminosalicylates are an option but the 
absence of a sphincter in the vagina makes their retention difficult, our patient responded well to biologic therapy. This case also highlights the contribution of local factors in the pathophysiology and disease activity of ulcerative colitis in the susceptible patient, including the gut and neovaginal microbiome.

\section{References}

[1] ACOG Committee on Adolescent Health Care. ACOG Committee Opinion. Number 274, July 2002. Nonsurgical diagnosis and management of vaginal agenesis. Obstet Gynecol. 2002 Jul; 100(1): 213-6. http://dx.doi.org/10.1016/S0029-7844(02)02158-0

[2] Roberts CP, Haber MJ, Rock JA. Vaginal creation for müllerian agenesis. Am J Obstet Gynecol. 2001 Dec; 185(6): 1349-52. http://dx.doi.org/10.1067/mob.2001.119075

[3] O'Connor JL, DeMarco RT, Pope JC 4th, Adams MC, Brock JW 3rd. Bowel Vaginoplasty in Children: A Retrospective Review. J Pediatr Surg. 2004 Aug; 39(8): 1205-8. http://dx.doi.org/10.1016/j.jpedsurg.2004.04.003

[4] Lima M, Ruggeri G, Randi B, Dòmini M, Gargano T, La Pergola E, Gregori G. Vaginal replacement in the pediatric age group: a 34-year experience of intestinal vaginoplasty in children and young girls. J Pediatr Surg. 2010 Oct; 45(10): 2087-91. http://dx.doi.org/10.1016/j.jpedsurg.2010.05.016

[5] Kapoor R1, Sharma DK, Singh KJ, Suri A, Singh P, Chaudhary H, Dubey D, Mandhani A. Sigmoid vaginoplasty: Long term results. Urology. 2006 Jun; 67(6): 1212-5.

[6] Parsons JK, Gearhart SL, Gearhart JP. Vaginal reconstruction utilizing sigmoid colon: Complications and long-term results. J Pediatr Surg. 2002 Apr; 37(4): 629-33. http://dx.doi.org/10.1053/jpsu.2002.31623

[7] Hiroi H, Yasugi T, Matsumoto K, Fujii T, Watanabe T, Yoshikawa H, Taketani Y. Mucinous adenocarcinoma arising in a neovagina using the sigmoid colon thirty years after operation: a case report. J Surg Oncol. 2001 May; 77(1): 61-4. http://dx.doi.org/10.1002/jso.1067

[8] Andryjowicz E, Qizilbash AH, DePetrillo AD, O'Connell GJ, Taylor MH. Adenocarcinoma in a cecal neovagina--complication of irradiation: report of a case and review of literature. Gynecol Oncol. 1985 Jun; 21(2): 235-9. http://dx.doi.org/10.1016/0090-8258(85)90258-6

[9] Gabarain G, Garcia-Naveiro R, Ponsky TA, Boulanger SC, Parry RL. Ulcerative colitis of the neovagina as a postsurgical complication of persistent cloaca. J Pediatr Surg. 2012 Jan; 47(1): e19-22. http://dx.doi.org/10.1016/j.jpedsurg.2011.09.060

[10] Hennigan TW, Theodorou NA. Ulcerative colitis and bleeding from a colonic vaginoplasty. J R Soc Med. 1992 Jul; 85(7): 418-9.

[11] Froese DP, Haggitt RC, Friend WG. Ulcerative colitis in the autotransplanted neovagina. Gastroenterology. 1991 Jun; 100(6): 1749-52.

[12] Descos L, Gillon J, André C, Papazian A, Lesbros F, Rochet Y, Mollard J. Simultaneous onset of ulcerative colitis in the rectum and in a segment of colon used for colpopoiesis: report of a case. Dis Colon Rectum. 1981 Oct; 24(7): 532-4. http://dx.doi.org/10.1007/BF02604317 